\title{
Adaptation and Validation of the Brazilian DASE and TUD Scales for Cocaine/Crack Users ${ }^{1}$
}

\author{
Suzana Dias Freire \\ Pontifícia Universidade Católica do \\ Rio Grande do Sul, Porto Alegre-RS, \\ Brazil
}

\author{
Dhiordan Cardoso da Silva \\ Pontifícia Universidade Católica do \\ Rio Grande do Sul, Porto Alegre-RS, \\ Brazil
}

\author{
Andressa Celente de Ávila \\ Pontificia Universidade Católica do \\ Rio Grande do Sul, Porto Alegre-RS, \\ Brazil
}

\author{
Carlo DiClemente \\ University of Maryland, USA
}

\author{
Margareth da Silva Oliveira \\ Pontificia Universidade Católica do Rio \\ Grande do Sul, Porto Alegre-RS, Brazil
}

\begin{abstract}
Self-efficacy for abstinence and temptation to use illicit drugs are demonstrably key elements of changing addictive behaviors. This study's aim was to analyze the psychometric evidence for the Brazilian adaptation of the scales Drug Abstinence Self-efficacy Scale (DASE) and Temptation to Use Drugs Scale (TUD). The sample was composed of 300 men treated for cocaine and crack addiction. Análise Factorial Exploratory and internal consistency demonstrated the existence of four factors in the DASE that explained 54\% of the total variation in the 24 items, and four factors in the TUD that explained 56\% of the total change in the variation. The Cronbach's alpha coefficient was at DSE .920 and TUD .927. The Brazilian adaptation of the scales showed appropriate evidence of validity in the sample of hospitalized individuals addicted to cocaine and crack.
\end{abstract}

Keywords: self-efficacy, abstinence, cocaine, crack (drug)

\section{Adaptação e Validação Brasileira das Escalas DASE e TUD para Usuários de Cocaína/Crack}

Resumo: Autoeficácia para abstinência e a tentação para uso de drogas são importantes elementos na mudança dos comportamentos aditivos. O objetivo do estudo foi analisar as evidências psicométricas da validação e adaptação brasileira das escalas Drug Abstinence Self-efficacy Scale (DASE) e Temptation to Use Drugs Scale (TUD). A amostra foi de 300 homens em tratamento pela dependência de cocaína e crack. A análise fatorial exploratória e de consistência interna demonstraram a existência de quatro fatores na DASE, explicando $54 \%$ da variação total dos 24 itens e quatro fatores na TUD explicando 56\% da variação total. O coeficiente alpha de Cronbach na DASE foi 0,920 e na TUD 0,927. A adaptação brasileira das escalas mostrou evidências de validade adequadas na amostra de dependentes de cocaína e crack internados.

Palavras-chave: autoeficácia, abstinência, cocaína, crack (droga)

\section{Adaptación y Validación Brasileña de las Escalas DASE y TUD para Usuarios de Cocaína/Crack}

\begin{abstract}
Resumen: Autoeficacia para abstinencia y la tentación para el consumo de drogas han sido elementos importantes en el cambio de las conductas adictivas. El objetivo del estudio fue analizar las evidencias psicométricas de la validación y adaptación brasileña de las escalas: Escala de Autoeficacia para Abstinencia de las Drogas (DASE) y Escala de Tentación de Utilizar Medicamentos (TUD). La muestra consistió en 300 hombres que reciben tratamiento para la adicción a la cocaína y el crack. El análisis factorial exploratorio y de consistencia interna mostraron la existencia de cuatro factores en la DASE, que explican el 54\% de la variación total de los 24 artículos; y cuatro factores que explican el 56\% de la variación total en la TUD. El coeficiente alfa de Cronbach fue 0,920 en la DASE y 0,927 en la TUD. La adaptación brasileña de las escalas muestra evidencias de validez adecuadas en la muestra de dependientes de la cocaína y el crack admitidos.
\end{abstract}

Palabras clave: autoeficacia, abstinencia, cocaína, crack (droga)

\footnotetext{
${ }^{1}$ Article derived from the master's dissertation of the first author, under the supervision of the fifth author, defended in 2009 by the Graduate Program in Psychology at the Pontifícia Universidade Católica do Rio Grande do Sul. ${ }^{2}$ Correspondence address:

Suzana Dias Freire. Avenida Ipiranga, 6681, prédio 11, sala 927, Partenon. CEP: 90619-900. Porto Alegre-RS, Brazil. E-mail: supsicologia@gmail.com
}

Drug misuse and dependence in Brazil, especially cocaine and crack, have been the focus of increasing attention due to the increased severity of its consequences. According to Ribeiro, Dualibi, Perrennoud, and Sola (2012), the prognosis is worse for those taking crack and cocaine together 
than for those who use either drug alone. According to a study conducted by Fundação Oswaldo Cruz [Fiocruz] (2013) on the profile of users of crack and similar drugs with a sample of 7,381 users, these individuals identified approximately 370,000 people that regularly use crack or similar forms of smoked cocaine in Brazil. This situation requires the development and improvement of efficient ways of prevention and intervention suitable to this reality. Actions to assess the constructs of the process of behavior change must be adapted to the Brazilian population's patterns of cocaine and crack use.

The Transtheoretical Model - MTT (Prochaska \& DiClemente, 1982) is an integrative and biopsychosocial framework for the process of intentional behavior change. Self-efficacy, an important cognitive aspect in the production of self-perception and an instrument in the self-regulation process and control of the environment itself (Bandura, Azzi, \& Polydoro, 2008), has become an important element to study factors related to drug addiction (Freire \& Oliveira, 2011). Both the MTT and Relapse Prevention (Marlatt \& Gordon, 1985) systematize the construct of self-efficacy in the understanding of addictions. In a literature review on self-efficacy related to drug use, Kadden and Litt (2011) reported that several studies demonstrated that self-efficacy is a predictor of outcomes, but there is still little consistency in the recommendation for interventions.

After the establishment of the MTT, temptation was understood as an urge to return to a previous behavior. According to studies conducted by Prochaska and DiClemente (1982), three factors are usually associated with the most common types of tempting situations: negative affect or distress, positive social situations, and craving. Temptation and self-efficacy are both important markers to assess the individual's commitment to the process of changing addictive behaviors (DiClemente, 2003). Thus, temptation to use illicit drugs is understood as a determining factor in relapse (Connors, DiClemente, Velasquez, \& Donovan, 2013).

DiClemente, Carbonari, Montgomery, and Hughes (1994) demonstrated the properties of the Alcohol Abstinence Self-efficacy Scale (AASE) with 266 alcoholics treated on an outpatient basis. The instruments had satisfactory outcomes in the measures of self-efficacy for alcohol abstinence and temptation to its use. This original version is composed of two complementary scales of 20 items each. Both contain the same items that describe a situation of substance use, and the response alternatives assign values (degrees) to the confidence in the ability to maintain abstinence in that situation using a 5-point Likert scale. In the other scale, they assign values to the temptation to use substances in that specific context. A structure with four subscales with five items each was obtained. Internal consistency for that sample of alcoholics was satisfactory. The subscales of self-efficacy showed the following Cronbach's alpha coefficients: Negative Affect (.88); Social/ Positive (.82); Physical and Other Concerns (.83); and Withdrawal/Urges (.81). The subscales of temptation obtained the following Cronbach's alpha coefficients: Negative Affect (.99); Social/Positive (.86); Physical and Other Concerns (.60); and Withdrawal/Urges (.70).

In the referred study, the authors presented the two sca- les as two domains of the same tool (AASE), although the analyses had been individually conducted, and independence was observed between them. Despite containing the same items, they are easily distinguishable and concern different constructs (DiClemente et al., 1994). Subsequent studies addressed these measures as correlated scales that can be used separately or together and used these tools in studies that use different methods and populations (Baumann et al., 2013; Glöckner-Rist, Lémenager, \& Mann, 2013; Greenfield, Venner, Kelly, Slaymaker, \& Bryan, 2012; Hoeppner, Kelly, Urbanoski, \& Slaymaker, 2011; Mckiernan et al., 2011; Stasiewicz, Schlauch, Bradizza, Bole, \& Coffey, 2012).

Validation and adaptation to different samples may increase the applicability and recognition of these scales as consistent and useful measures in studies, clinical interventions, planning and therapeutic monitoring. The study conducted by Freire and Oliveira (2011) contains a systematic literature review of articles that used tools for assessment of self-efficacy and temptation to the use of drugs. In the 13 articles identified, most tools indicated that hazardous situations were to be assessed regarding temptation to the use of drugs or self-efficacy for abstinence of drugs in general, without making a distinction between the substances. The present study defined a sample of hospitalized individuals addicted to cocaine and crack with the objective to perform the validation and cultural adaptation of the Drugs Abstinence Self-efficacy Scale (DASE) and the Temptation to Use Drugs Scale (TUD) (DiClemente et al., 1994) in the Brazilian context.

\section{Method}

\section{Participants}

The sample, which was obtained by convenience sampling, was composed of 300 men who used cocaine and crack and had been hospitalized to treat their chemical dependence. These men lived in the capital Porto Alegre, in the metropolitan region and in the inland region of the State of Rio Grande do Sul, Brazil. The participants were aged $18-56$ years $(M=$ 27.96; $S D=7.28)$, had completed at least the fifth grade of elementary school, and had sought treatment because of problems arising from the use of cocaine and crack. A minimum period of seven days of abstinence from psychoactive substances was required; periods of abstinence ranged between 7 and 120 days (Median =14). The length of institutionalization ranged from 1 to 65 days (Median $=10)$.

\section{Instruments}

The interview protocol was a semi-structured questionnaire for the collection of socio-demographic data related to the study, with the purpose of investigating the history of psychoactive substance use and the participants' current and past medical history.

The Drug Abstinence Self-efficacy Scale (DASE) and Temptation to Use Drugs Scale (TUD) were adapted for this study based on the Alcohol Abstinence Self-efficacy Scale (AASE) developed by DiClemente et al. (1994). They consist 
Freire, S. D., Silva, D. C., Ávila, A. C., DiClemente, C., \& Oliveira, M. S. (2017). Adaptation and Validation of Brazilian Scales DASE and TUD.

of self-administered questionnaires, of 24 items each, describing common situations within the context of drug use. The two scales involve the same 24 situations, with response alternatives offered in 5-point Likert scales. For each scale of temptation, the responses range from 1 - "Not at all tempted" to 5 - "Extremely tempted to use drugs." In the case of self-efficacy in maintaining abstinence, the responses ranged from 1 - "Not at all sure" to 5 - "Absolutely sure that I would not use drugs."

\section{Procedure}

Data collection. The process of scale adaptation comprised three stages: translation, brainstorming, and back-translation. First, the tools were translated from English to Brazilian Portuguese. The tools were applied to 10 individuals with the purpose of identifying confusing or ambiguous expressions. Next, brainstorming occurred, in which the original tools and the first version in Portuguese were presented to psychologists and Psychology students. Each item was verbally reproduced and separately discussed regarding possible misunderstandings. Finally, back-translation, in which the tools were translated to the original language by an expert in the English language, was performed. The raters compared the translations to verify whether the items reflected the constructs. This process resulted in the successful adaptation of DASE 20 items and TUD 20 items to Brazilian Portuguese.

The experts involved in the instrument adaptation process were Brazilian clinical psychologists, who inserted lines of research on addiction and considered the needs of therapeutic practice with groups of crack users. Analyzing the repertoire of skills, situation triggers and the environment into which the sample was placed (Coelho, Sá, \& Oliveira, 2015), they opted to enter four additional items to support some demands of clinical practice. Therefore, four more items were added to the first translation of 20 items, as follows: (21) When I think that no one will know if I use drugs; (22) When I have cash on hand or easy access to money; (23) When I fight with someone at home or at work; (24) When I think people do not trust me and do not believe that I am not using drugs.

Data analysis. The organization and analysis of information was performed with SPSS (Statistical Package for the Social Sciences), version 19.0. Exploratory analysis was conducted by descriptive statistics and frequency distribution, mean and standard deviation, calculation, or by median and interquartile range for quantitative variables. Cronbach's alpha coefficient was used to measure scale reliability. Varimax rotation was used in the exploratory factor analysis. The level of significance was $5 \%$.

\section{Ethical Considerations}

The project of the present study was submitted to and approved by the Research Ethics Committee and the Scientific Committee of the Pontifical Catholic University of Rio Grande do Sul, under no CEP 08/04387. After having been informed on the objectives of the study, as well as secrecy and anonymity procedures, all participants signed the Informed Consent Form.

\section{Results}

Of the total sample of 300 participants, $74.7 \%$ were single, $27.3 \%$ lived with their parents, $49 \%$ did not have children, and $74.3 \%$ had completed secondary education. We investigated whether the use of drugs had motivated the search for treatment: $75 \%$ of the participants were hospitalized to treat the use of crack and $25 \%$ to treat the use of cocaine.

\section{Reliability}

Internal consistency was assessed through the calculation of the Cronbach's alpha coefficient. The values showed satisfactory internal consistency, with alpha ranging from .718 to .927 . Table 1 shows these results.

Table 1

Cronbach's Alpha Coefficient of the Scales and Subscales $(N=300)$

\begin{tabular}{|c|c|c|c|}
\hline & Source & Cronbach's $\alpha$ & $\begin{array}{c}\text { Number of } \\
\text { items }\end{array}$ \\
\hline \multirow{5}{*}{ 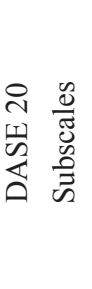 } & Negative Emotion & .829 & 5 \\
\hline & Social/Positive & .746 & 5 \\
\hline & Worries & .718 & 5 \\
\hline & Abstinence/Impulse & .736 & 5 \\
\hline & DASE 20 - Total & .900 & 20 \\
\hline \multirow{5}{*}{ 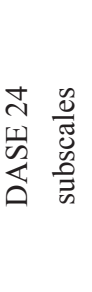 } & Negative Emotion & .859 & 7 \\
\hline & Social/Positive & .821 & 7 \\
\hline & Worries & .718 & 5 \\
\hline & Abstinence/Impulse & .736 & 5 \\
\hline & DASE 24 - Total & .920 & 24 \\
\hline \multirow{5}{*}{ 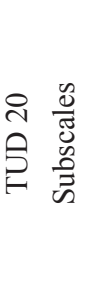 } & Negative Emotion & .841 & 5 \\
\hline & Social/Positive & .787 & 5 \\
\hline & Worries & .721 & 5 \\
\hline & Abstinence/Impulse & .760 & 5 \\
\hline & TUD 20 - Total & .908 & 20 \\
\hline \multirow{5}{*}{ 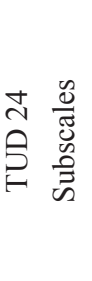 } & Negative Emotion & .872 & 7 \\
\hline & Social/Positive & .834 & 7 \\
\hline & Worries & .721 & 5 \\
\hline & Abstinence/Impulse & .760 & 5 \\
\hline & TUD 24 - Total & .927 & 24 \\
\hline
\end{tabular}

\section{Exploratory Factor Analysis}

Varimax rotation was used in the exploratory factor analysis. Eigen values greater than 1.0 were considered for the identification of the factors. In DASE 24, the final factor model had four factors that explained $54 \%$ of the total variation in the 24 items, and the main factor was responsible for $17.6 \%$ of the total variation. Table 2 shows the factors and 
factor loadings for each item of DASE 24.

Table 2

Factor Loading of the Items and its Allocation in the Factors (DASE 24)

\begin{tabular}{|c|c|c|c|c|}
\hline Items & 范 & 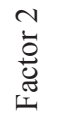 & 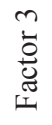 & 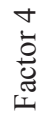 \\
\hline 3. When I am depressed or sad. & .574 & - & - & - \\
\hline 6. When I am stressed or worried & .758 & - & - & - \\
\hline $\begin{array}{l}\text { 14. When I feel I will not be able to } \\
\text { stand so much boredom or frustration. }\end{array}$ & .615 & - & - & - \\
\hline $\begin{array}{l}\text { 16. When I think things are not going } \\
\text { well for me. }\end{array}$ & .671 & - & - & - \\
\hline 18. When I feel very angry. & .662 & - & - & - \\
\hline $\begin{array}{l}\text { 23. When I fight with someone at } \\
\text { home or at work. }\end{array}$ & .628 & - & - & - \\
\hline $\begin{array}{l}\text { 24. When I think people do not trust } \\
\text { me and do not believe that I am not } \\
\text { using drugs. }\end{array}$ & .457 & - & - & - \\
\hline
\end{tabular}

\section{When I want to relax or when I am} on vacation.

8. When people offer me drugs in a social situation (e.g. parties or meetings with friends).

15. When I see other people using

drugs in a bar or at a party.

.440

17. When the people with whom I used to take drugs encourage me to use drugs.

20. When I am euphoric or celebrating with others.

21. When I think that no one will know if I use drugs.

22. When I have cash on hand or easy access to money.

\begin{tabular}{lcccc}
\hline 2. When I have a headache. & - & - & .752 & - \\
5. When I am concerned about someone. & - & - & .352 & - \\
9. When I dream about the use of drugs. & - & - & .306 & - \\
12. When I am physically tired. & - & - & .737 & - \\
13. When I feel a physical pain. & - & - & .774 & - \\
\hline $\begin{array}{l}\text { 1. When I feel anxious because have } \\
\text { stopped or reduced drug use. }\end{array}$ & - & - & - & .462 \\
7. When I feel like taking drugs just to \\
see what happens. \\
$\begin{array}{l}\text { 10. When I want to test my willpower } \\
\text { to control the use of drugs. }\end{array}$ \\
$\begin{array}{l}\text { 11. When I feel a physical need or } \\
\text { craving for drugs. }\end{array}$ \\
$\begin{array}{l}\text { 19. When the urge for drugs comes } \\
\text { unexpectedly. }\end{array}$
\end{tabular}

Factor 1 grouped items 3, 6, 14, 16, 18, 23 and 24 because they had factor loadings predominantly related to this factor. These items concerned negative affect and situations of displeasure. Factor 1 accounted for $17.6 \%$ of the total va- riation, and five of its items correspond to the original tool's Negative Emotions subscale. With the inclusion of two other items introduced in the adaptation process, this factor is composed of seven items that form the subscale of Negative Emotions. Factor 2 accounted for $13.5 \%$ of the variation in the 24 items, including the seven items that obtained a factor loading predominantly related to this factor: $4,8,15,17,20,21$ and 22. These items included the five items of the Social/Positive subscale and two other items added in the adaptation.

Responsible for $12.3 \%$ of the variation, factor 3 included the five items corresponding to the Worries subscale: 2, 5, 9, 12 and 13. Factor 4, which explained $10.4 \%$ of the total variation, was composed of five items with loads predominant for this domain: 1, 7, 10, 11 and 19. These items were originally grouped in the Abstinence/Impulse subscale. The grouping of factors corresponded to the constructs of the subscales of the original version, in which the four domains were called Negative Affect (Negative Emotions); Social/Positive (Social/Positive); Physical and Other Concerns (Worries); and Withdrawal/Urges (Abstinence/Craving).

In TUD 24, the final factor model presented four factors explaining $56 \%$ of the total variation of the 24 items, and the main factor was responsible for $20 \%$. Table 3 presents the factors and factor loadings of each item of TUD 24.

Table 3

Factor Loading of the Items and its Allocation in the Factors (TUD 24)

Items

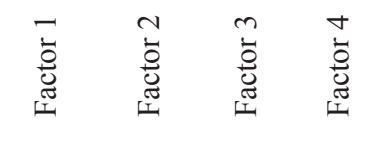

3. When I am depressed or sad.

.685

6. When I am stressed or worried. .684

14. When I feel I will not be able to stand so much boredom or frustration.

16. When I think things are not going well for me.

18. When I feel very angry.

23. When I fight with someone at home or at work.

24. When I think people do not trust me and do not believe that I .558 am not using drugs.

4. When I want to relax or when I am on vacation.

.607

8. When people offer me drugs in a social situation (e.g. parties or meetings with friends).

15. When I see other people using drugs in a bar or at a party.

17. When the people with whom I used to take drugs encourage me to use drugs.

20. When I am euphoric or celebrating with others.

\section{.699}

.713

.748

.748

$\begin{array}{llll}- & .053 & - & - \\ - & .746 & - & - \\ - & .800 & - & - \\ - & .763 & - & - \\ & & & \\ - & .480 & - & -\end{array}$

continue... 
Freire, S. D., Silva, D. C., Ávila, A. C., DiClemente, C., \& Oliveira, M. S. (2017). Adaptation and Validation of Brazilian Scales DASE and TUD.

\begin{tabular}{|c|c|c|c|c|}
\hline Items & 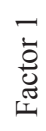 & $\begin{array}{l}N \\
\stackrel{0}{0} \\
\tilde{0} \\
\tilde{L}\end{array}$ & 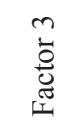 & 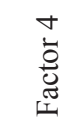 \\
\hline $\begin{array}{l}\text { 21. When I think that no one will } \\
\text { know if I use drugs. }\end{array}$ & - & .334 & - & - \\
\hline $\begin{array}{l}\text { 22. When I have cash on hand or } \\
\text { easy access to money. }\end{array}$ & - & .370 & - & - \\
\hline 2. When I have a headache. & - & - & .725 & - \\
\hline $\begin{array}{l}\text { 5. When I am concerned about } \\
\text { someone. }\end{array}$ & - & - & .453 & - \\
\hline $\begin{array}{l}\text { 9. When I dream about the use of } \\
\text { drugs. }\end{array}$ & - & - & .295 & - \\
\hline 12. When I am physically tired. & - & - & .758 & - \\
\hline 13. When I have a physical pain. & - & - & .370 & - \\
\hline $\begin{array}{l}\text { 1. When I feel anxious because I } \\
\text { have stopped or reduced drug use. }\end{array}$ & - & - & - & .484 \\
\hline $\begin{array}{l}\text { 7. When I feel like taking drugs } \\
\text { just to see what happens. }\end{array}$ & - & - & - & .754 \\
\hline $\begin{array}{l}\text { 10. When I want to test my will- } \\
\text { power to control the use of drugs. }\end{array}$ & - & - & - & .652 \\
\hline $\begin{array}{l}\text { 11. When I feel a physical need or } \\
\text { craving for drugs. }\end{array}$ & - & - & - & .311 \\
\hline $\begin{array}{l}19 . \text { When the urge for drugs comes } \\
\text { unexpectedly. }\end{array}$ & - & - & - & .607 \\
\hline Total items for each factor & 7 & 7 & 5 & 5 \\
\hline
\end{tabular}

The items with factor loadings predominantly related to factor 1 were $3,6,14,16,18,23$ and 24 . This factor explained $20.3 \%$ of the total variation, and five of these items correspond to the Negative Emotions subscale of the original tool, including two items inserted during the adaptation process. Thus, factor 1 included seven items that formed the Negative Emotions subscale. Factor 2 accounted for $13.3 \%$ of the variation, and it included the seven items that obtained a factor loading predominantly related to this factor: $4,8,15,17,20$, 21 and 22. The items contained five items of the Social/Positive subscale, with the addition of two other items during the adaptation process.

Corresponding to the Worries subscale, the items grouped in factor 3 included five items: $2,5,9,12$ and 13, explaining $12.3 \%$ of the variation. Responsible for $9.3 \%$ of the total variation, factor 4 contained five items with loadings predominantly related to this domain: 1, 7, 10, 11 and 19. The items were originally grouped in the Abstinence/Impulse subscale. The factor grouping corresponded to the constructs of the original version's subscales, whose four domains were designated Negative Affect (Negative Emotions); Social/Positive (Social/Positive); Physical and Other Concerns (Worries); and Withdrawal/Urges (Abstinence/Craving). During semantic adaptation, the inclusion of the four additional items aimed to adapt the tools to the Brazilian culture, which resulted in the Brazilian adaptation of the scales Drug Abstinence Self-efficacy Scale and Temptation to Use Drugs Scale in Portuguese.

\section{Discussion}

The present study investigated evidence of the validity of the versions of the DASE and TUD scales (20 and 24 items) that could be identified as adapted to the sample of individuals addicted to cocaine and crack. The process of semantic adaptation considered the particularities of Brazilian culture. The grouping of the items of the scales in factors corresponds to the constructs of the subscales of the original version, with four domains as follows: Negative Emotions; Social/Positive; Worries; Abstinence/Craving. In general, positive emotions triggered by easy access to money, and interpersonal circumstances favorable to the use of drugs without the recognition of the others, were identified among the social situations of high risk (Lowman, Allen, \& Miller, 1996). Two items added to the scales obtained loadings associated with factor 2, both in the DASE and in the TUD (item 21 "When I think that no one will know if I use drugs" and item 22 "When I have cash on hand or easy access to money"). This factor grouped items on positive emotions and social situations, which composed a subscale of seven items. The circumstances addressed by the items describe common situations of acceleration of temptation and decrease in self-efficacy. Situations involving money facilitate the purchase of drugs and thus differ from the reality experienced by alcoholics, who are usually regulars and can pay their bills later in the bars.

The negative emotions items represent developments of unpleasant situations (fights or feelings of disbelief), which are the most commonly reported by drug users who relapse (Marlatt \& Donovan, 2009). Two of the items included in the process of adaptation showed a factorial loading predominantly related to factor 1 in both scales: DASE 24 and TUD 24 (item 23 "When I fight with someone at home or at work." and item 24 "When I think people do not trust me and don't believe that I am not using drugs"). These items were grouped with others that corresponded to the Negative Emotions subscale. The relevance of the questions addressed in the four additional items is a justification for their assessment regarding self-efficacy and temptation to the use of illicit drugs. The versions that included these items showed that the tools adapted for this sample were easy-to-use and applicable tools for this sample. Semantic adaptation was performed in this study to adapt the tools to the Brazilian culture.

The internal consistency was adequate, with Cronbach's alpha coefficient values between .718 and .927. The total scales obtained excellent reliability: DASE $24(q=.920)$ and TUD $24(q=.927)$. DiClemente et al. (1994) obtained similar values in the sample of alcoholics treated on an outpatient basis, as follows: total AASE $(q=.92)$ and the subscales had alpha coefficients between .81 and .88 . In the study carried out by McKiernan et al. (2011), the 40-item version of the AASE was compared with the 12-item version developed by the authors for the same domains, in a population of 126 participants treated for use of alcohol and other drugs. Psychometric analysis showed satisfactory reliability and validity, with high correlations between the domains of DASE $(\alpha=.92)$ and TUD $(\alpha=.88)$ in the 40 -item version compared to the 12 -item version. 
The study conducted by Jason, Davis, and Ferrari (2007) obtained good internal consistency of these measures in a sample with hospitalized substance-dependent individuals using the AASE $(q=.98)$ and DASE $(q=.99)$ dealing with abstinence from drugs and alcohol. Baumann et al. (2013) investigated the psychometric properties of the eight-item version of the AASE in 414 users of alcohol. The results obtained showed alpha coefficients ranging from .74 to .81 in the four factors of the scale, that is, a moderate to high internal consistency. Nidecker, DiClemente, Bennett, and Bellack (2008) focused on cocaine-dependent individuals in a sample of 240 patients and used the short 12 -item version of DASE. The authors obtained excellent internal consistency in all the follow-up periods (alpha coefficient ranging from .91 to .93). Likewise, the 12-item Temptation to Use Drugs Scale (TUD) assessed the temptation to use cocaine, obtaining excellent reliability in the monitoring (follow-up) period (alpha coefficients between .91 and .93) in this sample.

With the inclusion of four new items, the Brazilian adaptation of the Drug Abstinence Self-efficacy Scale and Temptation to Use Drugs Scale became available. The evidence of validity obtained here can be observed even without the inclusion of the four new items. Analyses were performed separately for the 20- and 24-item versions to compare the adapted scales with the properties presented in the original 20 -item version. Furthermore, the good internal consistency confirms the applicability and validity of these scales in the sample of male patients hospitalized to treat cocaine and crack use.

The Brazilian adaptation of the referred scales was consistent with the constructs to be assessed in the sample of men hospitalized to treat cocaine and crack use who have completed at least the fifth grade of elementary education. The process of scale adaptation identified four hazardous situations not included in the original version, and items related to these situations were included. These factors correspond to negative emotions and to social or positive situations. From these elements, the calculations were performed in two versions that showed satisfactory evidence of validity. The coefficients demonstrated excellent internal consistency of the subscales and total scales in the two versions (20 and 24 items). The four-factor structure was obtained in the exploratory factor analysis of the two versions. The model involved considerable variation in the items, grouping them in the factors corresponding to the original subscales. The final versions of the DASE and TUD scales showed adequate evidence of validity in the sample of hospitalized cocaine- and crack-dependent male individuals.

\section{References}

Bandura, A., Azzi, R. G., \& Polydoro, S. (2008). Teoria social cognitiva: Conceitos básicos [Cognitive Social Theory: Basic Concepts] (R. C. Costa, Trad.). Porto Alegre, RS: Artmed.

Baumann, S., Gaertner, B., Schnuerer, I., Bischof, G., John, U., \& Freyer-Adam, J. (2013). How well do TTM mea- sures work among a sample of individuals with unhealthy alcohol use that is characterized by low readiness to change? Psychology of Addictive Behaviors, 27(3), 573-583. doi: $10.1037 / \mathrm{a} 0029368$

Coelho, L. R. M., Sá, L. G. C., \& Oliveira, M. S. (2015). Estratégias e habilidades de enfrentamento de usuários de crack em tratamento [Strategies and crack users coping skills treatment]. Revista de Psicologia da IMED, 7(2), 99-109. doi:10.18256/2175-5027/psico-imed.v7n2p99-109

Connors, G. J., DiClemente, C. C., Velasquez, M. M., \& Donovan, D. M. (2013). Substance abuse treatment and the stages of change: Selecting and planning interventions (2nd ed.). New York, NY: Guilford.

DiClemente, C. C. (2003). Addiction and change: How addictions develop and addicted people recover. New York, NY: Guilford.

DiClemente, C. C., Carbonari, J. P., Montgomery, R. P. G., \& Hughes, S. O. (1994). The Alcohol Abstinence Self-Efficacy scale. Journal of Studies on Alcohol, 55(2), 141-148. doi:10.15288/jsa.1994.55.141

Freire, S. D., \& Oliveira, M. S. (2011). Auto-eficácia para abstinência e tentação para uso de drogas ilícitas: Uma revisão sistemática [Self-efficacy for abstinence and temptation to use illicit drugs: A systematic review]. $P_{s i-}$ cologia: Teoria e Pesquisa, 27(4), 527-536. doi:10.1590/S010237722011000400018

Fundação Oswaldo Cruz. (2013). Maior pesquisa sobre crack já feita no mundo mostra o perfil do consumo no Brasil [Most research on crack ever made in the world shows the consumption profile in Brazil]. Retrieved from http:// portal.fiocruz.br/pt-br/content/maior-pesquisa-sobre-crack-j\%C3\%A1-feita-no-mundo-mostra-o-perfil-do-consumo-no-brasil

Glöckner-Rist, A., Lémenager, T., \& Mann, K. (2013). Reward and relief craving tendencies in patients with alcohol use disorders: Results from the PREDICT study. Addictive Behaviors, 38(2), 1532-1540. doi:10.1016/j.addbeh.2012.06.018

Greenfield, B. L., Venner, K. L., Kelly, J. F., Slaymaker, V., \& Bryan, A. D. (2012). The impact of depression on abstinence self-efficacy and substance use outcomes among emerging adults in residential treatment. Psychology of Addictive Behaviors, 26(2), 246-254. doi:10.1037/ a0026917

Hoeppner, B. B., Kelly, J. F., Urbanoski, K. A., \& Slaymaker, V. (2011). Comparative utility of a single-item versus multiple-item measure of self-efficacy in predicting relapse among young adults. Journal of Substance Abuse Treatment, 41(3), 305-312. doi:10.1016/j.jsat.2011.04.005

Jason, L. A., Davis, M. I., \& Ferrari, J. R. (2007). The need for substance abuse after-care: Longitudinal analysis of Oxford House. Addictive Behaviors, 32(4), 803-818. doi:10.1016/j.addbeh.2006.06.014 
Kadden, R. M., \& Litt, M. D. (2011). The role of self-efficacy in the treatment of substance use disorders. Addictive Behaviors, 36(12), 1120-1126. doi:10.1016/j.addbeh.2011.07.032

Lowman, C., Allen, J., \& Miller, W. R. (1996). Perspectives on precipitants of relapse. Addiction, 91(Suppl. 1), S1244. doi:10.1080/09652149638755

Marlatt, G. A., \& Donovan, D. M. (2009). Prevenção da recaída: Estratégias de manutenção no tratamento de comportamentos adictivos [Relapse prevention: Maintenance strategies in the treatment of addictive behaviors] (M. F. Lopes, Trans., 2nd ed.). Porto Alegre, RS: Artmed.

Marlatt, G. A., \& Gordon, J. R. (1985). Relapse prevention: Maintenance strategies in the treatment of addictive behaviors. New York, NY: Guilford.

McKiernan, P., Cloud, R., Patterson, D. A., Wolf, S., Golder, S., \& Besel, K. (2011). Development of a Brief Abstinence Self-Efficacy Measure. Journal of Social Work Practice in the Addictions, 11(3), 245-253. doi:10.1080/153325 6X.2011.593445

Nidecker, M., DiClemente, C. C., Bennett, M. E., \& Bellack, A. S. (2008). Application of the transtheoretical model of change: Psychometric properties of leading measures in patients with co-occurring drug abuse and severe mental illness. Addictive Behaviors, 33(8), 1021-1030. doi:10.1016/j.addbeh.2008.03.012

Prochaska, J. O., \& DiClemente, C. C. (1982). Transtheoretical therapy: Toward a more integrative model of change. Psychotherapy: Theory, Research and Practice, 19(3), 276-288. doi:10.1037/h0088437

Ribeiro, M., Dualibi, L. B., Perrennoud, L. O., \& Sola, V. (2012). Perfil do usuário e história natural do consumo [User profile and natural history of consumption]. In M. Ribeiro \& R. Laranjeira (Orgs.), O tratamento do usuário de crack [The treatment of crack users] (2nd ed., pp. 3949). Porto Alegre, RS: Artmed.

Stasiewicz, P. R., Schlauch, R. C., Bradizza, C. M., Bole, C. W., \& Coffey, S. F. (2012). Pretreatment changes in drinking: Relationship to treatment outcomes. Psychology of Addictive Behaviors, 27(4), 1159-1166. doi:10.1037/ a0031368
Suzana Dias Freire is a Master's Degree in Clinical Psychology from the Pontifícia Universidade Católica do Rio Grande do Sul, Porto Alegre-RS, Brazil

Dhiordan Cardoso da Silva is a Ph.D. in Psychiatry and Behavioral Sciences from the Universidade Federal do Rio Grande do Sul, Porto Alegre, Brazil

Andressa Celente de Ávila is a Master's Degree in Clinical Psychology from the Pontifícia Universidade Católica do Rio Grande do Sul, Porto Alegre-RS, Brazil.

Carlo DiClemente is a Professor of Psychology at the University of Maryland, Baltimore County.

Margareth da Silva Oliveira is Professor of the Faculty of Psychology at the Pontifícia Universidade Católica do Rio Grande do Sul, Porto Alegre-RS, Brazil.

Received: Feb. 7, 2016

1st Revision: Aug. 12, 2016

Approved: Aug. 23, 2016

How to cite this article:

Freire, S. D., Silva, D. C., Ávila, A. C., DiClemente, C., \& Oliveira, M. S. (2017). Adaptation and validation of the Brazilian DASE and TUD scales for cocaine/ crack users. Paidéia (Ribeirão Preto), 27(67), 93-99. doi: 10.1590/1982-43272767201711 